\title{
Application of DRIFT-FTIR spectroscopy for quantitative prediction of simple sugars in two local and two Floridian mango (Mangifera indica L.) cultivars in Kenya
}

\author{
Kennedy Olale ${ }^{1,2^{*}}$, Waudo Walyambillah', Salim Ali Mohammed ${ }^{1}$, Andrew Sila ${ }^{2}$ and Keith Shepherd ${ }^{2}$
}

\begin{abstract}
Background: Mangoes are fruits of nutritional importance in Kenya. The fruits vary in their sugars depending on cultivar type and ripening stage. Current methods of sugar content analysis are based on HPLC methods, which are accurate but expensive and time-consuming. We evaluated the potential of diffuse reflectance infrared Fourier transform (DRIFT) spectroscopy as a rapid tool for quantitative prediction of fructose and glucose sugars in the pulp of Kenyan mangoes.
\end{abstract}

Methods: Principal component analysis and partial least regression models were developed using the first derivative DRIFT spectra $\left(400-4000 \mathrm{~cm}^{-1}\right)$ to predict fructose and glucose sugars. A factorial analysis of variance compared effects of site (three locations), cultivar type (four cultivars), fruit position (inside/outside), and their interactions on fructose and glucose contents.

Results: The principal component analysis scores plot using components 1 and 2 explained 75 and $8 \%$ of the variance, respectively, with no clear grouping either by sites or cultivars. The PLS range for glucose was $R^{2}=0.80$, $\mathrm{SECV}=0.55$, and RPD $=11.52$ and fructose $R^{2}=0.70, \mathrm{SECV}=0.28$, and $\mathrm{RPD}=11.52$. Site $(F(2,265)=18.12, p<0.05$, $\eta 2=0.02)$, cultivar type $(F(3,256)=4.44, p<0.05, \eta 2=0.05)$, and fruit position $(F(1,259)=7.62, p<0.05, \eta 2=0.03)$ had a significant effect on glucose content and not on fructose content. However, interactions between these three factors were not significant, $p>0.05$. In general, fruits outside the canopy had higher fructose and glucose contents than those within the canopy.

Conclusions: DRIFTS coupled with chemometric techniques showed potential for prediction of fructose and glucose contents of mango fruits.

Keywords: Derivative spectra, Glucose, Fructose, HPLC, Tree canopy, Partial least squares, Mid-infrared spectroscopy

\section{Background}

Mango (Mangifera indica L.) is a popular fruit worldwide owing to its unique flavor, aroma, and appearance. The fruit offers great health benefits, due to the availability of vitamins $\mathrm{A}, \mathrm{C}$, and $\mathrm{E}$ and sugars as well as minerals such as potassium and phosphorus (Watson and Preedy 2010). In Kenya, there are only seven main cultivars commonly grown by farmers, two of which are local (Apple and

\footnotetext{
* Correspondence: kennedyolale@gmail.com

${ }^{1}$ Department of Chemistry, Jomo Kenyatta University of Agriculture and Technology, P.O. BOX 62000, Nairobi 00200, Kenya

${ }^{2}$ World Agroforestry Centre (ICRAF), P.O. BOX 30677, Nairobi 00100, Kenya
}

Ngowe) while the rest are introduced cultivars and includes Haden, Kent, Sensation, Tommy Atkins, and Van Dyke (Kehlenbeck et al. 2012). These introduced cultivars and their quality characteristics are not yet documented in detail (Kehlenbeck et al. 2010), although some initial work had been done by Griesbach (2003). The diversity in the composition of sugars in many mangoes vary according to the cultivar type (Rodriguez-saona et al. 2001), cultivation practice and climatic conditions (Muoki et al. 2009), ripeness at harvest (Mercadante and Rodriguez-Amaya 1998), and postharvest storage and treatment of the fruit (Manthey and Penelope 2009). Additionally, the variability 
in sugars amongst cultivars can also be due to fruit positioning on the tree (Asrey et al. 2007). Fruit position within the tree has an effect on quality as influenced by tree canopy (Asrey et al. 2007). The fruits that are sunexposed generally receive higher light intensity with relatively more UV and red light than in any other position of the tree (Jakopic et al. 2009). However, during fruit ripening stages, noticeable changes in mango fruit carbohydrate contents occur; the starch contents decreases while the sugar contents increases (Doreyappy-Gowda and Huddar 2001). At the unripe stage, the fruits have comparatively high starch content which gets hydrolyzed during ripening to give sugars such as fructose, glucose, sucrose, and maltose (Kudachikar et al. 2001). These sugars act as ripening and edibility indicators (Duarte et al. 2002). Fructose (Medlicott and Thompson, 1985) and glucose (Vazquez-Salinas and Lakshminarayana, 1985) have been identified as the main reducing sugars in mangoes. While sucrose has also been reported amongst the Floridian mango cultivars (Haden, Irwin, Kent, and Keitt) by Vazquez-Salinas and Lakshminarayana (1985).

Traditionally, the sugar content estimation in mango fruits amongst other fruits is based on different analytical techniques such as liquid chromatography, thin-layer chromatography, and gas chromatography for both qualitative and quantitative analyses (Liu et al. 2006). These mentioned methods of analysis provide accurate results, but are more labor-intensive, time-consuming, and expensive as well as unsuitable for field measurements (Liu et al. 2006). As a result, diffuse reflectance infrared Fourier transform infrared spectroscopy (DRIFT-FTIR) technique (4000-400 $\mathrm{cm}^{-1}$ range) often coupled with chemometrics could provide an alternative approach. DRIFTFTIR technique has an attractive feature of being noninvasive and potentially more rapid than the traditional methods (Duarte et al. 2002). In DRIFT-FTIR technique, samples are penetrated with infrared beam resulting in the generation of reflected specular and diffuse reflectance (Bruno 1999). The accessories attached to the DRIFTFTIR come with replaceable $\mathrm{KBr}$ or $\mathrm{ZnSe}$ detectors and preclude the need for pre-mixing the sample (Haberhauler and Gerzabek 1999). Several authors (Guthrie et al. 1997; Mahayothee et al. 2002; Saranwong et al. 2004; Saranwong et al. 2003; Saranwong and Kawano 2001; Schmilovitch et al. 2000) have suggested the potential of using DRIFTFTIR in evaluating internal quality attributes of different fruits. These internal quality attributes include sugars and organic acids in tomatoes (Beullens et al. 2006), watersoluble vitamins in tomatoes (Wojciechowski et al. 1998), organic acids, and polyphenol contents of apricot and apple fruits (Bureau et al. 2009). To ease the applicability of DRIFT-FTIR technique, often powdered and solid samples are used; thus, in this study, we used freeze-dried mango pulps to carry out our analysis. Freeze-drying is a method that provides an extended shelf life to the fruits (Marques et al. 2009). In this study, we evaluated the potential of DRIFT-FTIR spectroscopy technique to predict fructose, glucose, sucrose, and maltose in two local (Apple and Ngowe) and two Floridian (Kent and Tommy Atkins) mango cultivars. Additionally, we also considered three factors potentially influencing sugar contents: (i) site/location, (ii) fruit position, and (iii) cultivar types.

\section{Methods}

\section{Sample selection}

Four mango cultivars namely "Apple," "Kent," "Ngowe," and "Tommy Atkins" were chosen from three Kenya Agricultural Research Institute (KARI) orchard sites: "Thika," "Embu," and "Machakos" in Kenya. The four selected cultivars are widely grown in Kenya and are readily availability across KARI sites. The cultivars represent three different maturity types namely: early maturity (November to mid-January for Ngowe), mid-maturity (Tommy Atkins, late January-March), and late maturity cultivar (Apple) (Njuguna et al. 2009; Griesbach 2003). The three orchard sites are in different agro-ecological zonation. Five (5) trees of Kent, Ngowe, Apple, and Tommy Atkins cultivars were randomly selected per KARI orchard and ten (10) mango fruits sampled per tree. From the ten (10) mango fruits, five (5) were sun-exposed and five (5) were within the tree crown. All mango fruit samples were allowed to equilibrate to room temperature $\left(20^{\circ} \mathrm{C}\right)$ until they were fully ripe. Ripening was determined by subjective observation considering softness and peel color. Five (5) sun-exposed and five (5) mangoes within the tree crown were blended separately giving two sample set per tree. A total of 480 fruit samples were collected and freeze-dried. DRIFTS spectral measurements were recorded on all the samples. Out of this total, only $30 \%$ $(N=144)$ were subjected to wet analyses by HPLC and used to build a calibration model to predict the concentration of the remaining samples. The selection of $30 \%$ was based on the recorded IR spectral diversity using the Kennard and Stone (1969) algorithm included in the "prospectr" package 0.1.3 (Stevens and Ramirez-Lopez 2015) in R 3.0.1 (R Development Core Team 2014). Kennard-Stone algorithm is based on spectral distance measure and selects a set of samples having a uniform distribution over the predictor space and hence comprises all the sources of variation found in the recorded samples spectral library (Kennard and Stone 1969).

\section{Reagents}

Anhydrous $\mathrm{D}(-)$-fructose, $\mathrm{D}(+)$-glucose, sucrose, maltose (analytical grade), and acetonitrile (HPLC grade) were purchased from Sigma Aldrich (Kobian, Kenya). Fructose, glucose, sucrose, and maltose standard stock solutions were prepared by dissolving $2 \mathrm{~g}$ in $40 \mathrm{ml}$ of 
distilled water and $25 \mathrm{ml}$ HPLC grade acetonitrile. The volume was then topped to $100 \mathrm{ml}$ with distilled water.

\section{High-pressure liquid chromatography analysis of sugars}

The extraction procedure of the sugars (glucose, fructose, sucrose, and maltose) was carried out as described by Medlicott and Thompson (1985) with slight modifications. Briefly, $2 \mathrm{~g}$ of freeze-dried mango pulp was carefully weighed $( \pm 0.0001 \mathrm{~g})$. It was transferred into a $100 \mathrm{ml}$ volumetric flask and homogenized with $40 \mathrm{ml}$ distilled water and $25 \mathrm{ml}$ HPLC grade acetonitrile. The mixture was made to $100 \mathrm{ml}$ using distilled water. One milliliter of this solution was then clarified by centrifuging at $10000 \mathrm{rpm}$ for $20 \mathrm{~min}$. The homogenate was filtered through $0.45 \mathrm{pm}$ millipore filters. Filtered sample was then measured for constituent sugar concentrations by HPLC using an Agilent 1200 system (Agilent Technologies, Japan). The injected sample volume was $10 \mu \mathrm{L}$ with the HPLC settings as follows: column Supelcosil ${ }^{\text {ta }}$ $\mathrm{LC}-\mathrm{NH}_{2}, 5 \mu \mathrm{m}(25 \mathrm{~cm} \times 4.6 \mathrm{~mm})$, mobile phase of $0.75 \%$ acetonitrile in water, flow rate of $1.0 \mathrm{ml} / \mathrm{min}$, run time of $10 \mathrm{~min}$, column temperature of $35{ }^{\circ} \mathrm{C}$, and refractive index detection (Agilent 1200 model). To check the reproducibility of the HPLC measurements, each sample was measured twice.

\section{Fourier transform infrared spectroscopy spectral acquisition}

Approximately $2 \mathrm{mg}$ of homogenized freeze-dried mango pulps were transferred to the DRIFT sample holder cup. The mixture filled the DRIFT accessory sample holder cup, and the top was leveled off. The samples were scanned in the mid-IR on a Bruker Fourier transform spectrometer (Alpha) equipped with a $\mathrm{KBr}$ detector (ICRAF laboratory). Samples were scanned from 4000 to $400 \mathrm{~cm}^{-1}$ (2500 to $\left.25,000 \mathrm{~nm}\right)$ at $4 \mathrm{~cm}^{-1}$ resolution and corrected against the background spectrum of the gold standard. The sample holder cup was cleaned between measurements with deionized water and dried with a lint-free tissue.

\section{Spectral data processing}

Several pre-processing techniques were tested including: no spectral data pre-processing, first derivative (1stDer) and multiplicative scatter correction (MSC). Principal component analysis (PCA) was used to investigate sample spectra and eliminate the noisy spectra (aberrant spectra due to a problem of acquisition). The partial least square (PLS) regression method was used to develop models for predicting sugar composition of mango fruits. Representative calibration set was selected according to spectra diversity using (Kennard and Stone 1969) algorithm for developing calibration models between the spectral data and laboratory reference values, while the prediction set was used for validation. The absorption band around 2379.8 and $2350.8 \mathrm{~cm}^{-1}$, due to carbon dioxide, was discarded prior to the calculation and non-informative regions tentatively purged before calibration models were developed.

\section{Model evaluation}

Partial least square regression (PLSR) models using leave-one-out cross-validation method were fitted using $\mathrm{R}$ software version 3.1.0 ( $\mathrm{R}$ Development Core Team 2014) and used to develop and evaluate the predictive ability of the models. Leave-one-out cross-validation method works by using a single training set, where one sample is removed at a time and the rest of the samples are used to build a model, and the process iterated until each sample has been left out once. Then the removed sample is treated as an unknown, and the response variable or property of interest is predicted (Brereton 2003). To evaluate the predictive ability of the partial least squares regression (PLSR) models developed, the residual predictive deviation (RPD), defined as the ratio between the standard deviation (SD) of the population, the root mean square error of calibration (RMSEC), the root mean square error of prediction (RMSEP), and the correlation coefficient $(R)$ were used. The RMSEC was calculated as follows:

$$
\mathrm{RMSEC}=\sqrt{\frac{1}{n_{\mathrm{c}}-1} \sum_{i=1}^{n_{\mathrm{c}}}\left(\hat{y}_{\mathrm{i}}-y_{\mathrm{i}}\right)^{2}}
$$

where $\hat{y}$ is the prediction value of the $i^{\text {th }}$ observation, $y_{\mathrm{i}}$ is the measured value of $i^{\text {th }}$ observation, and $n_{\mathrm{c}}$ is the number of the observations in the calibration set.

For the prediction set, the RMSEP was calculated as follows:

$$
\text { RMSEP }=\sqrt{\frac{\sum_{i=1}^{n_{\mathrm{p}}}\left(y_{\mathrm{i}}-\hat{y}_{\mathrm{i}}\right)^{2}}{n_{\mathrm{p}}}}
$$

where $\hat{y}_{\mathrm{i}}$ is the prediction value of the $i^{\text {th }}$ observation, $y_{\mathrm{i}}$ is the measured value of the $i^{\text {th }}$ observation, and $n_{\mathrm{p}}$ is the number of the observations in the prediction set.

Correlation coefficients between the prediction and the measurement value were calculated as follows:

$$
r=\sqrt{\frac{\sum_{i=1}^{n}\left(\hat{y}_{\mathrm{i}}-y_{\mathrm{i}}\right)^{2}}{\sum_{i=1}^{n}\left(\hat{y}_{\mathrm{i}}-\bar{y}\right)^{2}}}
$$

where $\hat{y}_{\mathrm{i}}$ and $y_{\mathrm{i}}$ are the prediction and measurement value of the sample $i$ in the calibration and prediction sets, $\bar{y}$ is the mean of the reference measurement results for all samples in calibration and prediction sets, and $n$ 
is the number of the observations in calibration and prediction set. Acceptable models should have low RMSEC and RMSEP, high $\mathrm{R}$, and small differences between RMSEC and RMSEP. Large differences indicate the introduction of too many PLS factors (latent variables) in the model. The predicted residual error sum of squares (PRESS) was computed from the error in prediction. PRESS values are indications of how closely a model fits the calibration data.

A factorial ANOVA was performed on predicted fructose and glucose concentrations to examine the effect of fruit position, cultivar type, and location of mango fruit sugars. For both analyses, when a significant difference $(p<0.05)$ was detected in some variable, Tukey's mean test was applied to evaluate the difference between the samples. In addition, the two fruit position means were compared by independent sample $t$ test at a significant level of $0.05(p<0.05)$ using SPSS software version 19. Hierarchical component analysis (HCA) (minimum variance method; squared Euclidean distances) was carried out on the auto-scaled dataset of cultivars, in order to understand the variation within each cultivar.

\section{Results}

High-pressure liquid chromatography analyses

Four sugars present in the freeze-dried mango samples were quantified: two monosaccharides (fructose and glucose) and two disaccharides (sucrose and maltose), Fig. 1. Some separated peaks were not identified because the reference compounds were not available in the laboratory. Good separation was achieved similar to previously reported by the equipment manufacturer, although the peak heights of some sugars were quite small due to its absorbance being very low at the set wavelength. Four calibration curves for each sugar were established: for fructose $(y=187,848 \times-5298.11, R=$ $0.9998)$, glucose $\left(y=9 \mathrm{E}+06 \times-2008.4, R^{2}=0.9955\right)$, sucrose $(y=2.32030 \times-79,390.00, R=0.9999)$, and maltose $\left(y=8 \mathrm{E}+06 \times-4331.9, R^{2}=0.9638\right)$.

\section{DRIFT spectral features}

Figure 2 shows the overlaid DRIFT-FTIR spectrum of freeze-dried mango pulp. By comparing the first derivative corrected spectra of the fructose and glucose standards, distinct peaks were found in the wavenumber
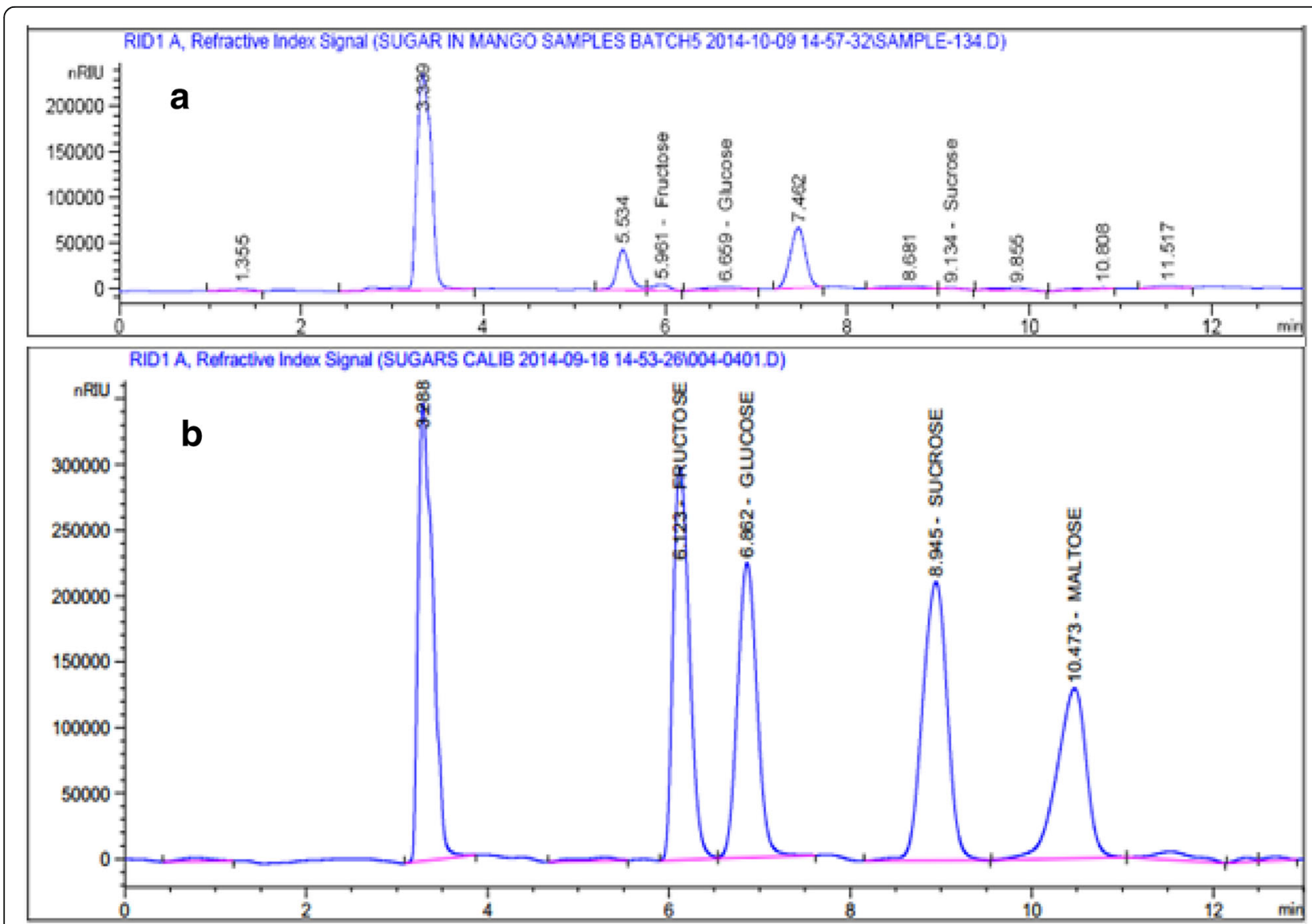

Fig. 1 Example of an HPLC chromatogram of $\mathbf{a}$ freeze-dried mango pulp and $\mathbf{b}$ four sugar standards for each retention time. a Overlay of raw DRIFT-FTIR spectrum. b Overlay of first derivative DRIFT-FTIR spectrum, acquired from 4000 to $450 \mathrm{~cm}^{-1}$ 

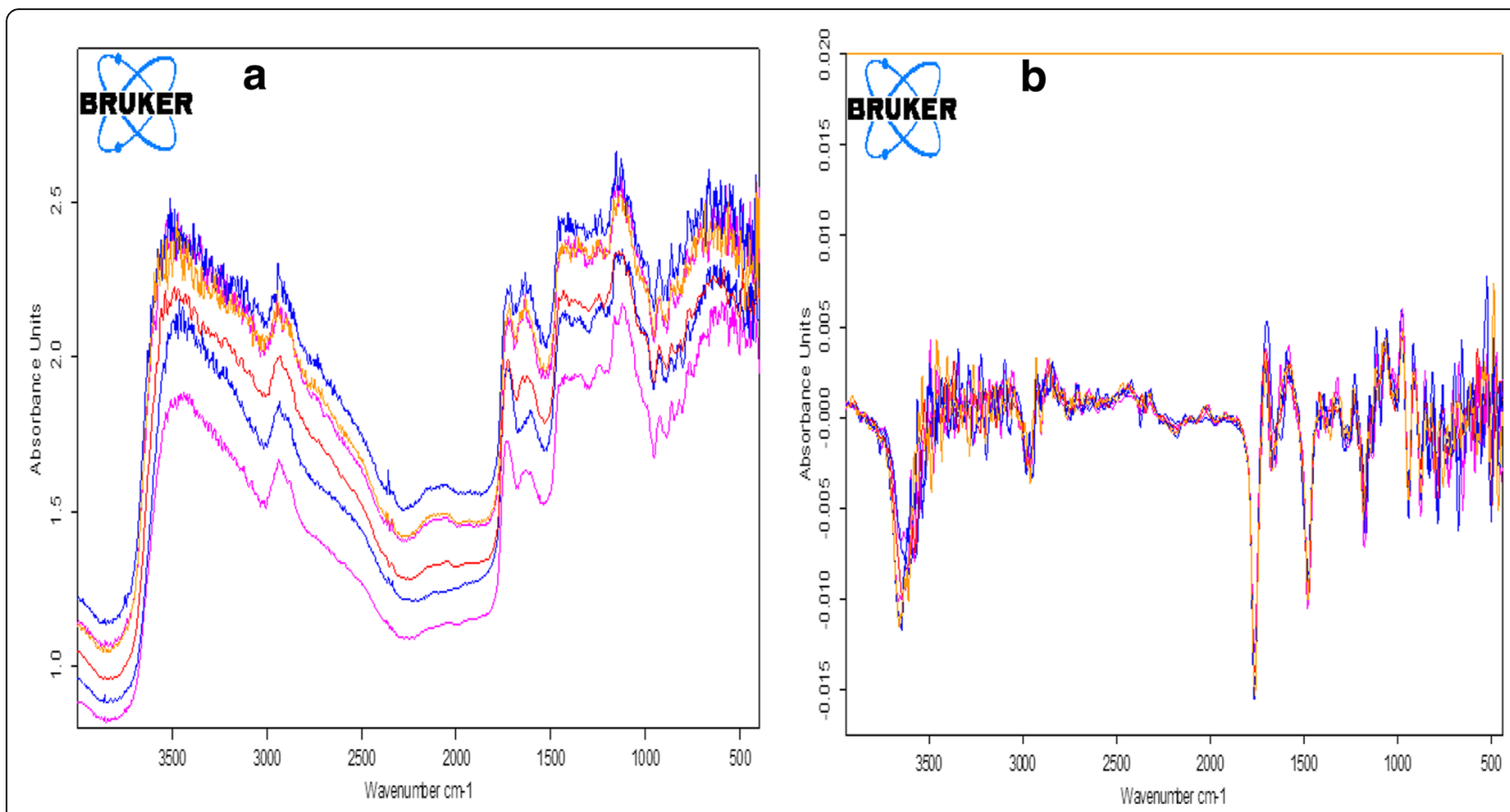

Fig. 2 Plot of factor loading values for the principal components used to fructose and glucose from MIR spectra

range of $1500-750 \mathrm{~cm}^{-1}$. In this region, the specific absorption for each carbohydrate was identified. The characteristic bands of fructose have specific maxima at 966, 979, 1063, and $1082 \mathrm{~cm}^{-1}$, the maximal absorption peak at $1063 \mathrm{~cm}^{-1}$ (Fig. 2). Glucose have specific maxima at 991, 1033, 1078, 1107, and $1149 \mathrm{~cm}^{-1}$, with $1033 \mathrm{~cm}^{-1}$ peak having the highest absorption which is a charateristic of $\mathrm{C}-\mathrm{O}$ stretch vibration (Fig. 2). Sucrose spectra bands include 928, 1007, 1054, 1123, 1362, and $1427 \mathrm{~cm}^{-1}$ with key peaks of $994 \mathrm{~cm}^{-1}$. The most intense peak of fructose or sucrose around 1063, or 1053 and $995 \mathrm{~cm}^{-1}$, respectively, is characteristic to the $\mathrm{C}-\mathrm{O}$ stretch vibration (Fig. 2). The absorption regions between $3700-2800 \mathrm{~cm}^{-1}$ and $1800-1470 \mathrm{~cm}^{-1}$ are assigned to water.

\section{Model establishment and descriptive statistics}

The descriptive statistics of the chemical parameters evaluated from the freeze-dried mango pulp samples reference data are shown in Table 1. Glucose concentrations showed significant variation in the calibration dataset $(\mathrm{CV}=96.27 \%$ with $\min .=0.65 / 100 \mathrm{~g}$ and $\max .=$ $23.10 / 100 \mathrm{~g}$ of freeze-dried weight) as well as sucrose $(\mathrm{CV}=75.00 \%$ with $\mathrm{min} .=0.06 / 100 \mathrm{~g}$ and $\max .=6.34 /$ $100 \mathrm{~g}$ of freeze-dried weight).

Although multiplicative scattering correction (MSC) option was tested, optimal models for sugars (fructose, glucose, sucrose, and maltose) were obtained when the first derivative spectral pre-treatments were used (Table 2). The spectral ranges used for the glucose model were different from those used for fructose and sucrose, even though full range spectra were tested for all sugars.

The calibration statistics for the PLS models developed indicated good to fair correlations of fructose content $\left(R^{2}=0.70, \mathrm{SECV}=0.28, \mathrm{RPD}=11.52\right)$, glucose $\left(R^{2}=0.80, \quad \mathrm{SECV}=0.55, \quad \mathrm{RPD}=11.52\right)$, sucrose $\left(R^{2}=\right.$ $0.64, \mathrm{SECV}=2.74, \mathrm{RPD}=0.18)$, and maltose $\left(R^{2}=0.37\right.$, $\mathrm{SECV}=0.39, \mathrm{RPD}=2.03$ ) (Table 2). The $R^{2}$ values for fructose and glucose were high both requiring three factors to build the PLS model.

Considering the obtained RPD values, a range between 2.40 and 3.00 is considered poor. Thus, the models for sucrose and maltose could only be applied for very rough screening (Williams and Norris 2002). The RPD value greater than five could be considered good for

Table 1 Means, ranges, and SD of mango samples used in calibration and cross-validation statistics

\begin{tabular}{llcllll}
\hline Sugars & Method & Samples & Mean & SD $( \pm)$ & CV \% & Range (max-min) \\
\hline Fructose & MIR & 67 & 13.17 & 3.57 & 27.11 & $31.12-6.21$ \\
& HPLC & & 13.70 & 5.96 & 43.50 & $39.78-8.94$ \\
Glucose & MIR & 38 & 3.43 & 3.23 & 94.17 & $21.63-1.46$ \\
& HPLC & & 3.78 & 3.64 & 96.27 & $23.10-0.65$ \\
Sucrose & MIR & \multirow{2}{*}{34} & 1.87 & 1.29 & 68.98 & $6.22-0.06$ \\
& HPLC & & 2.68 & 2.01 & 75.00 & $6.34-0.06$ \\
Maltose & MIR & 41 & 3.28 & 0.79 & 24.09 & $6.21-2.29$ \\
& HPLC & & 4.43 & 2.23 & 50.34 & $9.46-1.08$ \\
\hline
\end{tabular}

$\mathrm{CV}=[\mathrm{SD} /$ mean $] \times 100$ : amounts are $\mathrm{g} / 100 \mathrm{~g}$ of freeze dry weight 
Table 2 Calibration and cross-validation statistics for sugars on freeze-dried mango samples

\begin{tabular}{lllllllll}
\hline Sugars $(N)$ & Pre-treatments & Wavelength $\left(\mathrm{cm}^{-1}\right)$ & $R^{2}$ & SECV & RPD & $F$ & Bias & PRESS \\
\hline Fructose (67) & 1stDer & $4000-500$ & 0.70 & 0.28 & 12.73 & 3 & -0.53 & 0.0048 \\
Glucose (38) & 1stDer & $750-1500$ & 0.80 & 0.55 & 11.52 & 3 & -0.34 & 0.0155 \\
Sucrose (34) & 1stDer & $4000-500$ & 0.64 & 7.24 & 0.18 & 8 & -0.81 & 0.0499 \\
Maltose (41) & 1stDer & $750-1500$ & 0.37 & 0.39 & 2.03 & 3 & -1.15 & 0.0944 \\
\hline
\end{tabular}

F PLS factors/number of partial least squares factors used in calibration equation, $R^{2}=$ coefficient of determination, SEC standard error of cross-validation; Bias difference between mean of the MIR-predicted values and the mean of the reference method values, $N$ number of samples, $R P D$ (std. dev. of reference data)/(std. error of cross-validation), PRESS predictive residual sum of squares

quantitative applications (Williams and Norris 2002). Accordingly, we considered the obtained RPD values for fructose and glucose good enough for quantitative predictions. It is desirable for a good model to have low error of calibration and few factors as possible (Fig. 3).

\section{Principal component analysis using the first derivative DRIFT spectra}

The principal component analysis results related to the dataset containing first derivative spectra are reported (Fig. 4); for this PCA, the same wavenumber regions and data pre-treatment were used as for the PLS calibrations. The method using the DRIFT spectra partly showed mango samples from KARI-Thika and KARI-Embu in similar clusters but was not distinctively able to group samples based on the location (Fig. 4). The first two components containing the first derivative spectra explain only $83.50 \%$ (PC1 $75.40+\mathrm{PC} 28.10$ ) of the total variance. In an attempt to further explore and possibly improve the qualitative discrimination of the mango cultivars, PCA scores using cultivar type were developed with the same spectral regions and data pre-treatment as used previously; however, no crisp clustering of the PCA scores by cultivar type was observed (Fig. 4).

\section{Quantitative prediction of fructose and glucose sugars across cultivars}

PLS models developed were used to predict fructose and glucose concentrations of four mango cultivars across three sites and the data used to determine the interaction effect between the site and cultivar type on fructose and glucose contents. The means and standard deviations of the predicted fructose and glucose concentration are presented in Fig. 5. The sites were KARI-Thika, KARI-Machakos, and KARI-Embu and cultivars consisted of four types: Apple, Tommy Atkins, Ngowe, and Kent. The analysis of variance for site showed significant difference in the mean glucose

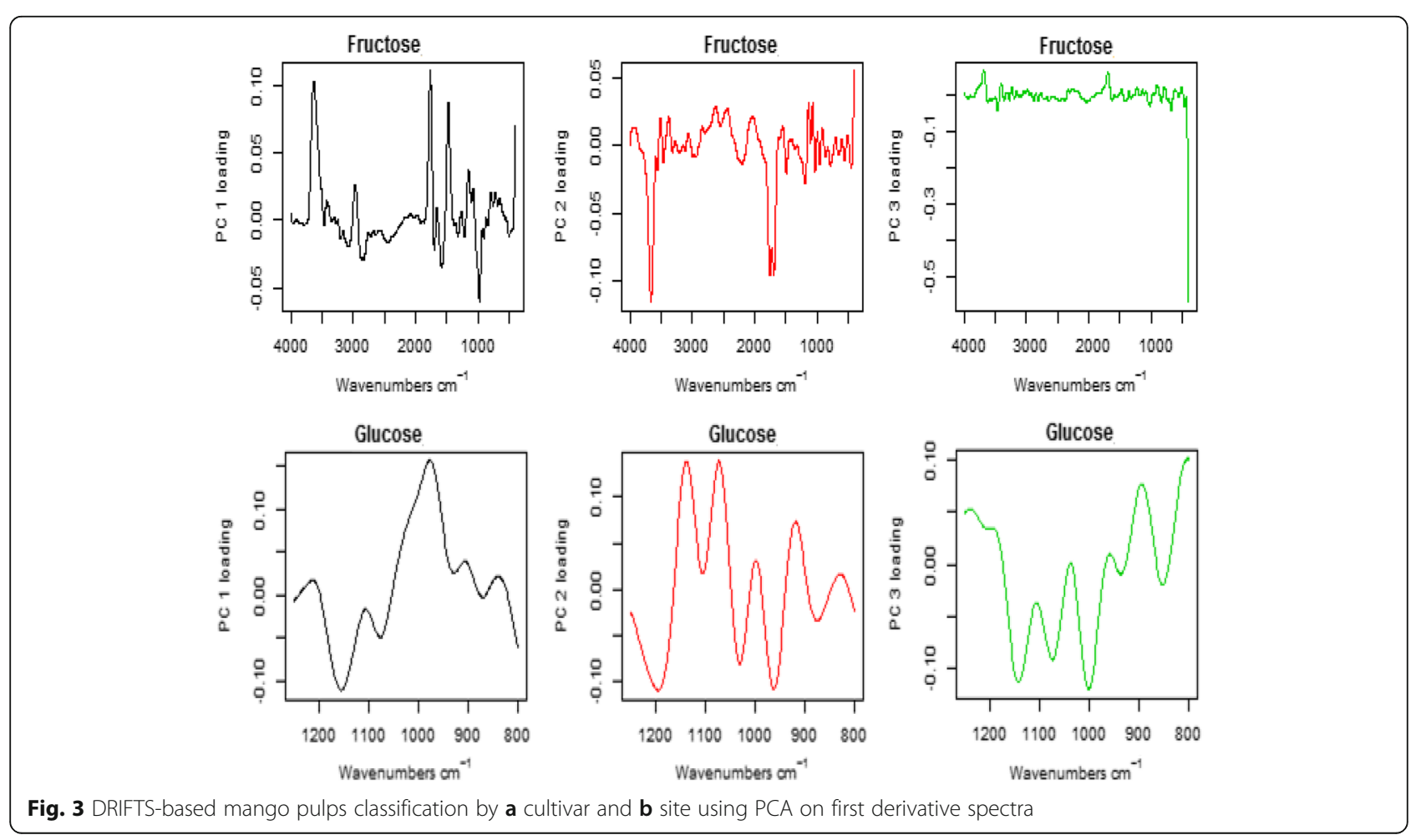



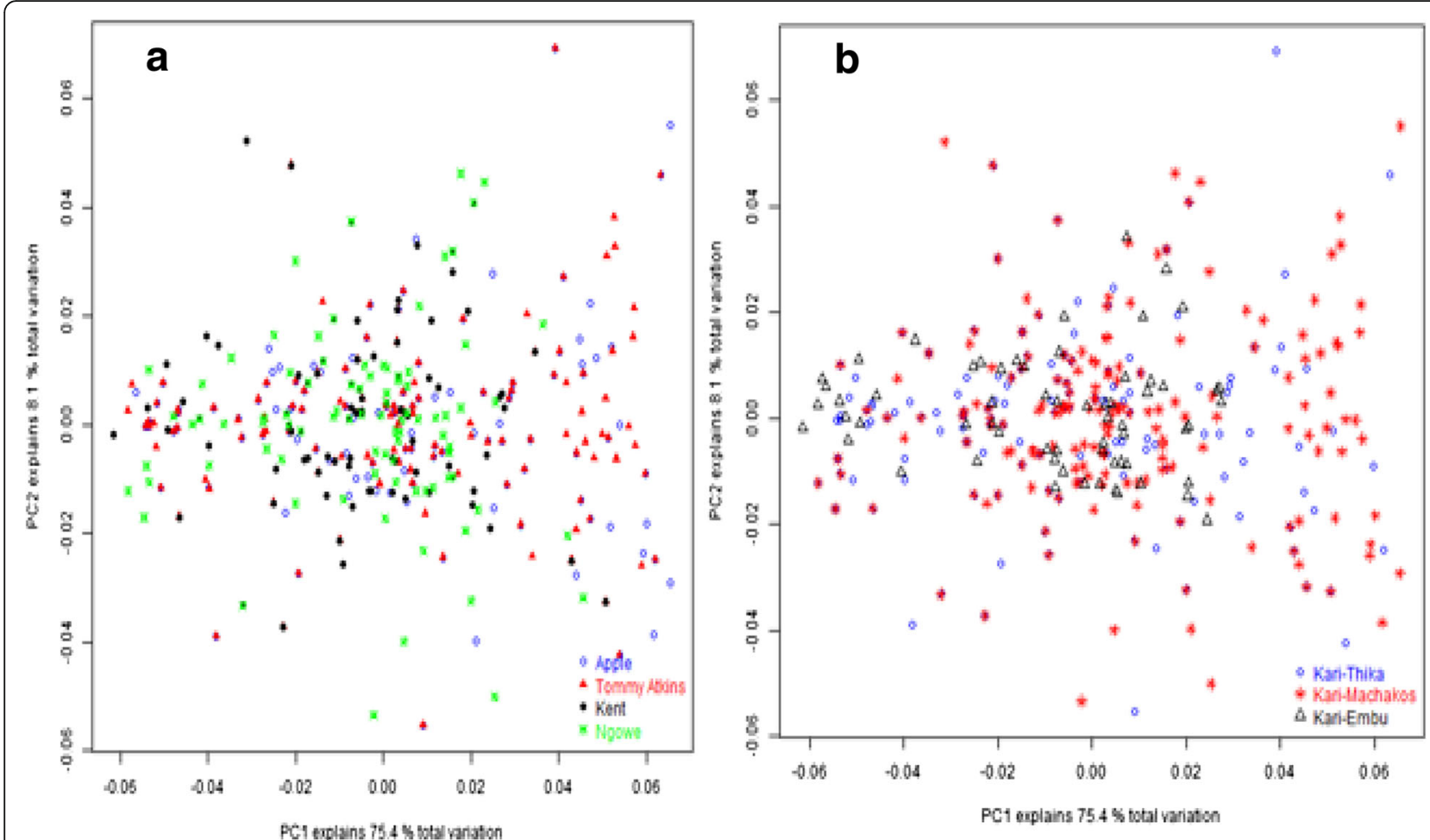

Fig. 4 Comparisons of mean fructose and glucose contents of Apple, Tommy Atkins, Ngowe, and Kent mango cultivars across KARI-Thika, KARIMachakos, and KARI-Embu locations. Values represent mean \pm Std. dev. Different letters denote significant differences $(p<0.05)$; values bearing the same superscript are not significantly different from one another. Number of pulps samples analyzed for Apple in KARI-Thika (20), KARIMachakos (51), and KARI-Embu (17); Tommy Atkins in KARI-Thika (20), KARI-Machakos (37), and KARI-Embu (12); Ngowe in KARI-Thika (9) and KARIMachakos (58); Kent in KARI-Thika (8), KARI-Machakos (18), and KARI-Embu (26). Amounts are per $100 \mathrm{~g}$ of freeze dry weight, $N=$ number of trees per cultivar in each site

content, $F(2,265)=18.12, p<0.05, \eta^{2}=0.02$; and no significant difference in the mean fructose content, $F(2$, 265) $=2.45, p>0.05, \eta^{2}=0.02$. The mean glucose content amongst the cultivar types was significantly different, $F(3,256)=4.44, p<0.05, \eta^{2}=0.05$, while the mean fructose content showed no significant difference amongst the cultivar type, $F(3,256)=2.47, p=0.06, \eta^{2}=$ 0.03 . There was no significant difference in mean glucose and fructose content resulting from the interaction between site and cultivar types, $F(5,265)=0.08, p>0.05$, and $F(5,265)=.720, p<0.05$, respectively. Post hoc comparisons using the Tukey HSD test indicated that the mean glucose contents of Kent cultivars in KARIMachakos $($ mean $=3.51, \quad \mathrm{SD}=1.38)$ and KARI-Embu (mean $=3.41, \mathrm{SD}=1.27$ ) were significantly higher than the mean glucose contents of Kent cultivars in KARI-Thika $($ mean $=3.51, \mathrm{SD}=1.38)$ (Fig. 5). However, there was no significant difference in mean fructose contents between the cultivar with the highest content: Kent (mean $=13.59$, $\mathrm{SD}=1.13)$ in Kari-Embu and that with lowest fructose contents and Tommy Atkins (mean $=12.08, \mathrm{SD}=1.17$ ) in KARI-Machakos. When all the cultivars were pooled together, Tommy Atkins had significantly lower mean fructose contents (mean $=12.23, \mathrm{SD}=1.16)$ than Apple $($ mean $=12.99, \mathrm{SD}=1.14)$, Ngowe $($ mean $=13.27, \mathrm{SD}=$ 1.11 ), and Kent (mean $=13.15, \mathrm{SD}=1.13$ ). In a general trend, Apple cultivars in KARI-Machakos (mean $=3.02$, $\mathrm{SD}=1.29)$ and KARI-Embu (mean $=3.12, \mathrm{SD}=1.21$ ) had significantly higher glucose contents than those of Apple cultivars in KARI-Thika (mean $=2.32, \mathrm{SD}=1.26)$, $p<0.05$. Tommy Atkins cultivars in both KARIMachakos $($ mean $=3.18, \quad \mathrm{SD}=1.47)$ and KARI-Embu (mean $=3.18, \mathrm{SD}=1.46)$ had significantly higher mean glucose contents than those of a similar cultivar in KARIThika (mean $=2.40, \mathrm{SD}=1.34$ ), $p=0.017$. Ngowe cultivars in KARI-Machakos (mean $=3.39, \mathrm{SD}=1.30$ ) had significantly higher glucose content than Ngowe cultivars in KARI-Thika $(\mathrm{mean}=2.69, \mathrm{SD}=1.26), p=0.013$. Ngowe cultivar was not found in KARI-Embu orchards hence not included in the analysis (Fig. 5). Kent cultivars in both KARI-Machakos $($ mean $=3.51, \quad \mathrm{SD}=1.38)$ and KARIEmbu (mean $=3.41, \mathrm{SD}=1.27$ ) had significantly higher mean glucose contents than Kent cultivars in KARI-Thika (mean $=2.60, \mathrm{SD}=1.21$ ), $p=0.027$. There were no significant differences in the mean fructose concentrations amongst cultivars type and the sites. However, the cultivar 


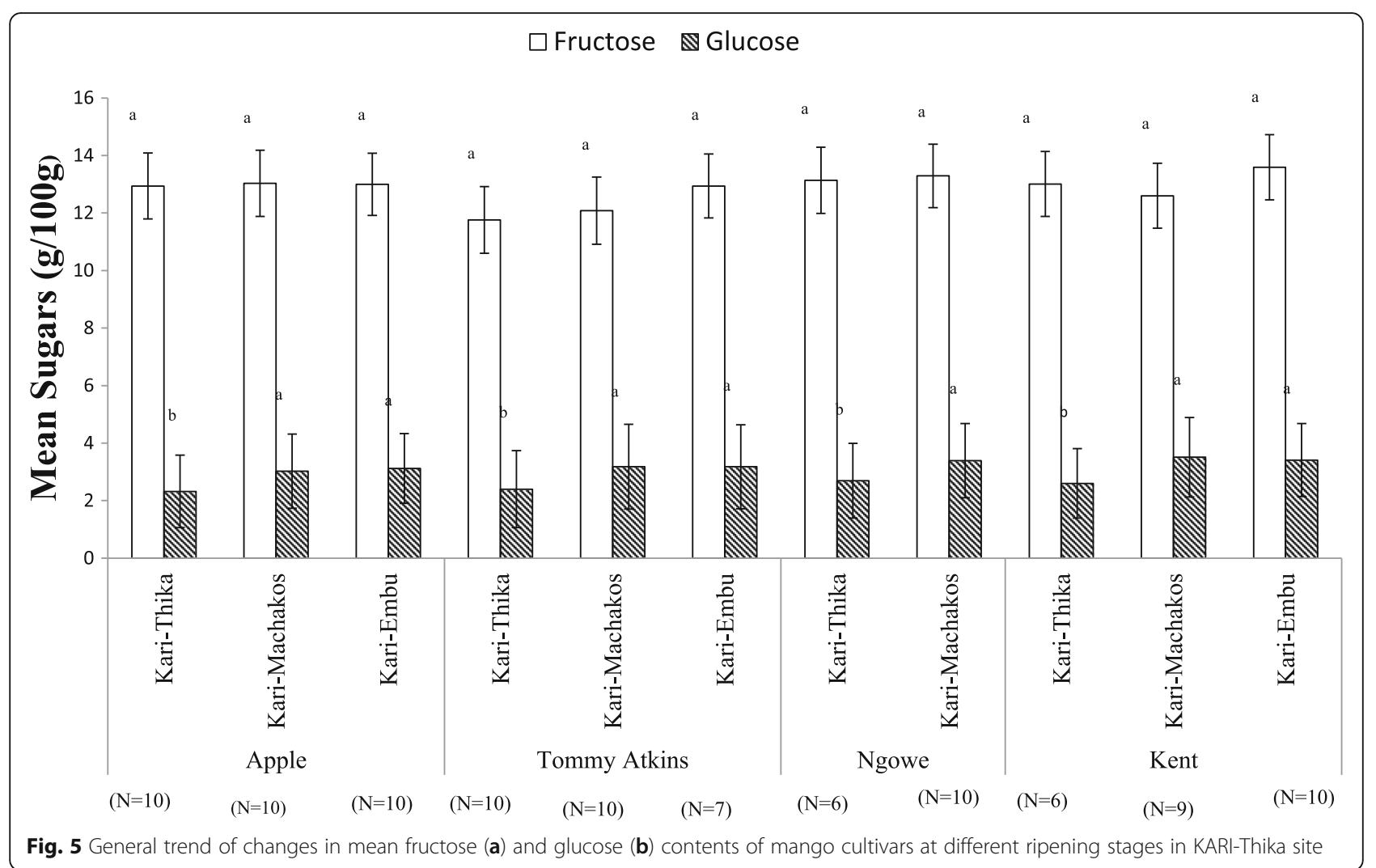

with higher content of fructose was Kent (mean $=13.59$, $\mathrm{SD}=1.13$ ) in KARI-Embu (Fig. 5).

\section{Variation of fructose and glucose concentrations with fruit position}

The two fruit positions, sun-exposed and within the crown, were compared in terms of mean fructose and glucose contents with a goal of determining the variations within mango cultivars. Sun-exposed fruits resulted in higher fructose and glucose concentrations in all mango cultivars than mango fruits that were within the crown (Table 3). A factorial ANOVA compared the main effects of fruit position, site and cultivar type, and the interaction effect between fruit position, site and cultivar type on fructose, and glucose contents. The main effect for fruit position showed a significant difference on mean glucose content, $F(1,259)=7.62, p<0.05, \eta^{2}=$ 0.03 , and no significant effect on the mean fructose content, $F(1,259)=1.85, p>0.05, \eta^{2}=0.01$. The interaction between fruit position and cultivar for mean fructose, $F(3,259)=0.13, p>0.05$, and glucose, $F(3,265)=$ 2.32, $p>0.05$ as well as the interaction between fruit position and site for fructose, $F(3,259)=0.36, p>0.05$, and glucose, $\mathrm{F}(3,265)=0.40, p>0.05$ was also not significant. Moreover, the interaction between fruit position and site and cultivar type was not significant for both fructose, $F(10,259)=0.19, p<0.05, \eta^{2}=0.01$ and glucose contents, $F(3,259)=1.23, p>0.05, \eta^{2}=0.046$. To test the effect of fruit position (sun-exposed vs. within the crown) on fructose and glucose contents, the mean sugar contents for the two groups were compared using an independent $t$ test. Table 3 provides a summary of these results. There was a significant difference in the mean glucose content of the sun-exposed (mean $=3.74$, $\mathrm{SD}=1.34$ ) and within the crown (mean $=2.68, \mathrm{SD}=$ 1.51) conditions; $t(36)=3.0, p=0.005$ for Tommy Atkins in KARI-Machakos. The statistical analysis shows a general trend that sun-exposed fruits had higher fructose and glucose contents compared to the mango fruits that were within the crown even if there were no significant difference between sun-exposed fruits and within the crown fruits for the other cultivars.

\section{Compositional variation in fructose and glucose concentrations at different ripening stage}

Variations in two major simple sugars, fructose and glucose, observed in the fruits of four mango cultivars at three ripening stages: green maturing, intermediate, and fully ripe are shown in Fig. 6. A factorial ANOVA compared the main effects of ripening stage, fruit position and cultivar type, and the interaction effect between ripening stage and cultivar type and ripening stage and fruit position on mean fructose and glucose contents. The main effect for ripening stage showed a significant 
Table 3 An independent $t$ test results examining the means difference in fructose and glucose contents between two fruit positions in four mango cultivars across the three sites

\begin{tabular}{|c|c|c|c|c|c|c|c|c|c|}
\hline Site & $\begin{array}{l}\text { Cultivar type } \\
\text { (no. of trees) }\end{array}$ & Fruit position & $N$ & $\begin{array}{l}\text { Fructose } \mathrm{g} / 100 \mathrm{~g} \\
\text { mean } \pm \text { std. dev }\end{array}$ & $t$ stat (df) & $p$ value & $\begin{array}{l}\text { Glucose } \mathrm{g} / 100 \mathrm{~g} \\
\text { mean } \pm \mathrm{std} . \mathrm{dev}\end{array}$ & $t$ stat (df) & $p$ value \\
\hline \multirow[t]{8}{*}{ KARI-Thika } & \multirow[t]{2}{*}{ Apple (10) } & Sun exposed & 14 & $12.94 \pm 1.16$ & \multirow[t]{2}{*}{$0.001(18)$} & \multirow[t]{2}{*}{0.999} & $2.28 \pm 1.29$ & \multirow[t]{2}{*}{$0.539(18)$} & \multirow[t]{2}{*}{0.597} \\
\hline & & Within crown & 6 & $12.94 \pm 1.12$ & & & $2.42 \pm 1.17$ & & \\
\hline & \multirow[t]{2}{*}{ Tommy Atkins (10) } & Sun exposed & 11 & $11.67 \pm 1.14$ & \multirow[t]{2}{*}{$0.230(18)$} & \multirow[t]{2}{*}{0.821} & $2.60 \pm 1.32$ & \multirow[t]{2}{*}{$1.185(19)$} & \multirow[t]{2}{*}{0.251} \\
\hline & & Within crown & 9 & $11.86 \pm 1.20$ & & & $2.17 \pm 1.32$ & & \\
\hline & \multirow[t]{2}{*}{ Ngowe (6) } & Sun exposed & 6 & $13.36 \pm 1.17$ & \multirow[t]{2}{*}{$0.487(7)$} & \multirow[t]{2}{*}{0.641} & $2.94 \pm 1.32$ & \multirow[t]{2}{*}{$1.528(7)$} & \multirow[t]{2}{*}{0.17} \\
\hline & & Within crown & 3 & $12.71 \pm 1.11$ & & & $2.25 \pm 1.13$ & & \\
\hline & \multirow[t]{2}{*}{ Kent (6) } & Sun exposed & 2 & $13.10 \pm 1.06$ & \multirow[t]{2}{*}{$0.089(6)$} & \multirow[t]{2}{*}{0.932} & $3.17 \pm 1.11$ & \multirow[t]{2}{*}{$2.078(6)$} & \multirow[t]{2}{*}{0.083} \\
\hline & & Within crown & 6 & $12.98 \pm 1.15$ & & & $2.43 \pm 1.18$ & & \\
\hline \multirow[t]{8}{*}{ KARI-Machakos } & \multirow[t]{2}{*}{ Apple (10) } & Sun exposed & 24 & $13.32 \pm 1.15$ & \multirow[t]{2}{*}{$1.233(50)$} & \multirow[t]{2}{*}{0.223} & $3.13 \pm 1.33$ & \multirow[t]{2}{*}{$1.058(51)$} & \multirow[t]{2}{*}{0.295} \\
\hline & & Within crown & 27 & $12.78 \pm 1.15$ & & & $2.93 \pm 1.25$ & & \\
\hline & \multirow[t]{2}{*}{ Tommy Atkins (10) } & Sun exposed & 19 & $12.31 \pm 1.15$ & \multirow[t]{2}{*}{$0.544(43)$} & \multirow[t]{2}{*}{0.589} & $3.74 \pm 1.34$ & \multirow[t]{2}{*}{$3.002(36)$} & \multirow[t]{2}{*}{0.005} \\
\hline & & Within crown & 18 & $11.84 \pm 1.19$ & & & $2.68 \pm 1.51$ & & \\
\hline & \multirow[t]{2}{*}{ Ngowe (10) } & Sun exposed & 29 & $13.58 \pm 1.11$ & $1.647(56)$ & 0.105 & $3.43 \pm 1.25$ & $0.550(58)$ & 0.585 \\
\hline & & Within crown & 29 & $13.01 \pm 1.10$ & & & $3.36 \pm 1.32$ & & \\
\hline & Kent (9) & Sun exposed & 9 & $12.77 \pm 1.11$ & $0.470(16)$ & 0.643 & $3.61 \pm 1.40$ & $0.370(16)$ & 0.716 \\
\hline & & Within crown & 9 & $12.43 \pm 1.15$ & & & $3.41 \pm 1.36$ & & \\
\hline KARI-Embu & Apple (10) & Sun exposed & 7 & $13.29 \pm 1.09$ & $1.606(18)$ & 0.517 & $3.24 \pm 1.18$ & $0.664(15)$ & 0.517 \\
\hline & & Within crown & 10 & $12.80 \pm 1.08$ & & & $3.03 \pm 1.24$ & & \\
\hline & Tommy Atkins (7) & Sun exposed & 5 & $13.46 \pm 1.07$ & $0.359(11)$ & 0.726 & $3.37 \pm 1.63$ & $0.444(10)$ & 0.666 \\
\hline & & Within crown & 7 & $12.59 \pm 1.12$ & & & $3.04 \pm 1.36$ & & \\
\hline & Kent (10) & Sun exposed & 12 & $13.58 \pm 1.15$ & $0.026(25)$ & 0.979 & $3.39 \pm 1.26$ & $0.175(26)$ & 0.863 \\
\hline & & Within crown & 14 & $13.60 \pm 1.11$ & & & $3.43 \pm 1.30$ & & \\
\hline
\end{tabular}

$p$ values indicate a significant difference between means of sun-exposed and within crown fruits ( $p \leq 0.05$; independent sample $t$ test); amounts are per $100 \mathrm{~g}$ of freeze dry weight. $N=$ number of pulp samples analyzed

difference on mean glucose content, $F(2,407)=29.44$, $p<0.05, \eta^{2}=0.13$, and no significant effect for fructose content, $F(2,407)=1.426, p>0.05, \eta^{2}=0.01$. The interaction between ripening stage and cultivar type was not significant for both fructose, $F(6,407)=0.82, p>0.05$, $\eta^{2}=0.012$, and glucose contents, $F(6,407)=1.21$, $p>0.05, \eta^{2}=0.02$. Similarly, the interaction between ripening stage and fruit position was not significant for both mean fructose, $F(3,259)=0.92, p>0.05, \eta^{2}=0.01$, and mean glucose contents, $F(3,265)=1.18, p>0.05$, $\eta^{2}=0.01$. Significant variation was established between mean of glucose content in freeze-dried mango pulp at different ripening stages, $p<0.05$, However, there was no significant difference in mean fructose contents at different ripening stages (Table 4). At the intermediate stage, the concentration of fructose sugar in Kent, Tommy Atkins, and Ngowe cultivars were higher than in fully ripe and green maturing ripening stage. The fructose level ranged from $12.62 \pm 1.13 / 100 \mathrm{~g}$ in Tommy Atkins to $13.68 \pm 1.03 / 100 \mathrm{~g}$ in Kent.

This suggests that intermediate ripe mango fruits were much richer in starch/maltodextrin compared to fully ripe mango fruits (Kansci et al. 2003). Conversely, glucose concentrations were higher for fully ripe mango fruits for all the cultivars (Fig. 6), ranging from high of $3.30 \pm 1.32 / 100 \mathrm{~g}$ Kent cultivar to low of $2.86 \pm 1.30 /$ $100 \mathrm{~g}$ for Apple cultivars (Table 4). As the ripening continues, the level of glucose concentrations showed a significant $(p \leq 0.00)$ increase from green maturity/intermediate maturity to fully ripe stage for fruits of Apple, Tommy Atkins, Ngowe, and Kent $(p \leq 0.02)$ (Fig. 6).

\section{Discussions}

\section{Fructose and glucose spectral characteristics and PLSR} models

Selection of appropriate spectral regions (Fig. 2) to build up the calibration model using PLS is critical, and the range selected should highlight the optical responses of targeted sugars. Similar studies by Max and Chapados (2007) on IR waveband assignment for glucose and fructose identified endocyclic $\mathrm{C}-\mathrm{O}$ bands around $1080 \mathrm{~cm}^{-1}$. However, by selectively using only these marker wavebands, a quantitative prediction of individual sugars would be difficult considering the overlap of these peaks 


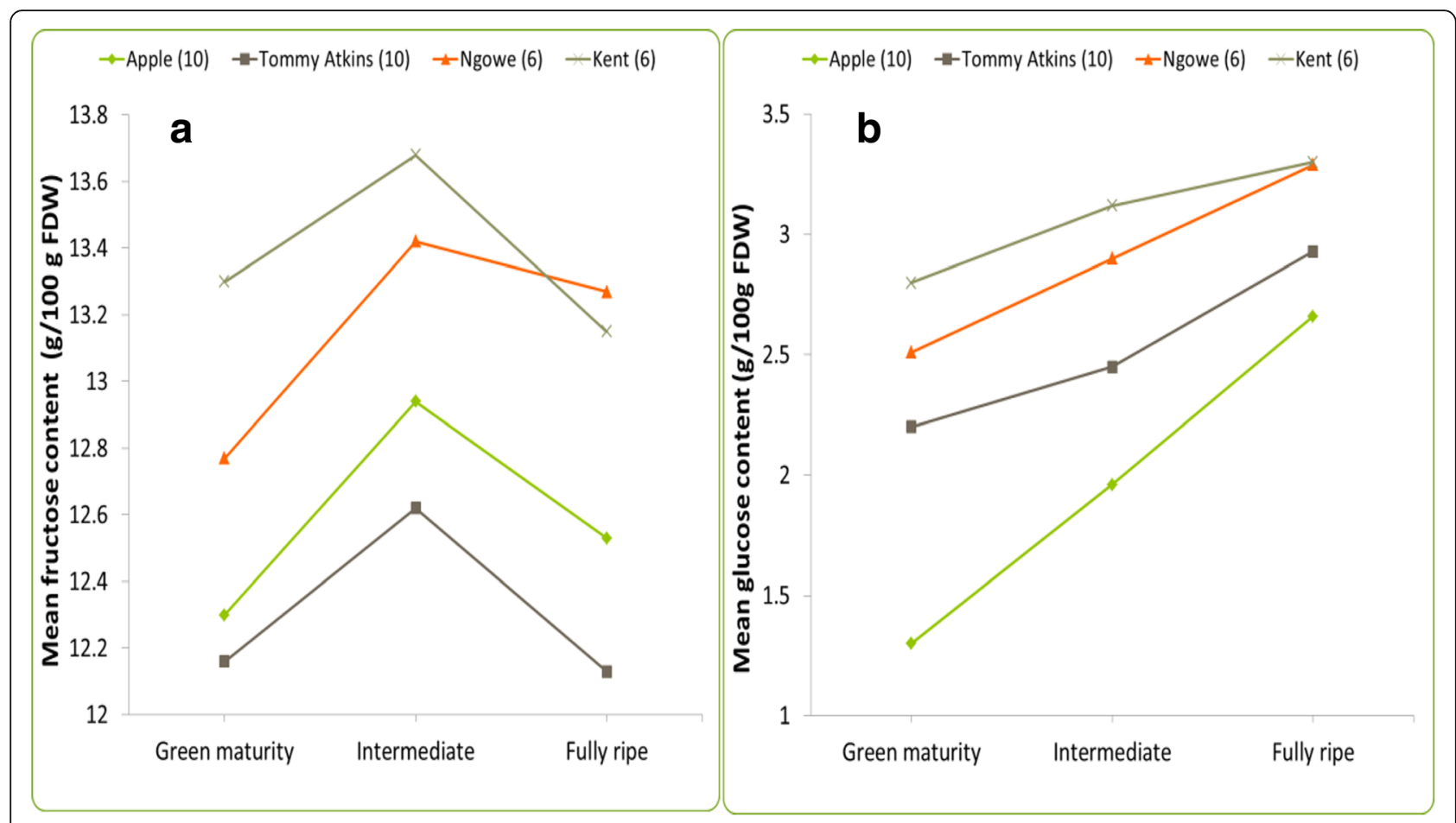

Fig. 6 General trend of changes in mean fructose and glucose contents of mango cultivars at different ripening stages in KARI-Thika Site

with different absorption intensities. Leopold et al. (2009) identified absorption bands between 885 and $1500 \mathrm{~cm}^{-1}$ as characteristic for carbohydrate specific bonds and functional groups. These bands correspond to stretching, bending, and wagging molecular vibrations as well as molecular rotations, and may be used to

Table 4 Fructose and glucose contents of four mango cultivars at three stages of maturity in KARI-Thika site, mean \pm SD $(N)$

\begin{tabular}{|c|c|c|c|c|}
\hline $\begin{array}{l}\text { Cultivar } \\
\text { (no. of trees) }\end{array}$ & Sugars & Green maturity & Intermediate & Fully ripe \\
\hline \multirow[t]{2}{*}{ Apple (10) } & Fructose & $\begin{array}{l}12.30 \pm 1.13^{a} \\
(29)\end{array}$ & $\begin{array}{l}12.53 \pm 1.13^{a} \\
(25)\end{array}$ & $12.94 \pm 1.15^{\mathrm{a}}(20)$ \\
\hline & Glucose & $\begin{array}{l}1.96 \pm 1.34^{\mathrm{b}} \\
(29)\end{array}$ & $\begin{array}{l}2.66 \pm 1.28^{\mathrm{a}} \\
(25)\end{array}$ & $2.86 \pm 1.30^{\mathrm{a}}(20)$ \\
\hline \multirow[t]{2}{*}{$\begin{array}{l}\text { Tommy Atkins } \\
\text { (10) }\end{array}$} & Fructose & $\begin{array}{l}12.16 \pm 1.20^{a} \\
(23)\end{array}$ & $\begin{array}{l}12.62 \pm 1.13^{\mathrm{a}} \\
(24)\end{array}$ & $12.13 \pm 1.16^{\mathrm{a}}(20)$ \\
\hline & Glucose & $\begin{array}{l}2.20 \pm 1.34^{b} \\
(23)\end{array}$ & $\begin{array}{l}2.45 \pm 1.21^{\mathrm{ab}} \\
(24)\end{array}$ & $2.93 \pm 1.46^{\mathrm{a}}(20)$ \\
\hline \multirow[t]{2}{*}{ Ngowe (6) } & Fructose & $\begin{array}{l}12.77 \pm 1.16^{\mathrm{a}} \\
(11)\end{array}$ & $\begin{array}{l}13.42 \pm 1.14^{\mathrm{a}} \\
\text { (7) }\end{array}$ & $13.27 \pm 1.11^{\mathrm{a}}(9)$ \\
\hline & Glucose & $\begin{array}{l}2.51 \pm 1.15^{b} \\
(11)\end{array}$ & $\begin{array}{l}2.90 \pm 1.30^{\mathrm{ab}} \\
(7)\end{array}$ & $3.29 \pm 1.30^{\mathrm{a}}(9)$ \\
\hline \multirow[t]{2}{*}{ Kent (6) } & Fructose & $\begin{array}{l}13.30 \pm 1.13^{\mathrm{a}} \\
(22)\end{array}$ & $\begin{array}{l}13.68 \pm 1.03^{\mathrm{a}} \\
(8)\end{array}$ & $13.15 \pm 1.13^{\mathrm{a}}(8)$ \\
\hline & Glucose & $\begin{array}{l}2.80 \pm 1.34^{\mathrm{a}} \\
(22)\end{array}$ & $\begin{array}{l}3.12 \pm 1.15^{\mathrm{a}} \\
(8)\end{array}$ & $3.30 \pm 1.32^{\mathrm{a}}(8)$ \\
\hline
\end{tabular}

A factorial ANOVA followed by LSD and Tukey post hoc. Means with the same superscript letter in a row are not significantly different $(p \leq 0.05)$. Amounts are per $100 \mathrm{~g}$ of freeze dry weight. $N$ number of pulp samples analyzed fingerprint a given compound in a mixture (Leopold et al. 2009). It is worth to mention that, in this study, fructose and glucose band assignments are in agreement with those presented by Guo and Zhang (2004). The region from 600 to $1500 \mathrm{~cm}^{-1}$ has been identified as the region for $\mathrm{C}-\mathrm{O}$ and $\mathrm{C}-\mathrm{C}$ groups vibration and the carbohydrates region (Guo and Zhang 2004). We build the PLSR model for fructose around $4000-500 \mathrm{~cm}^{-1}$, while for glucose model was build around $750-1500 \mathrm{~cm}^{-1}$. In a general trend, wide-spread range of fructose and glucose concentrations were observed amongst the other sugars (Table 1) with fructose as the main simple sugars. The wide concentration range in sugars made it possible for FTIR-DRIFT technique to be used for calibration development of diverse dataset. The obtained $R^{2}$ values (Table 2) were comparable with ranges obtained by Xie et al. (2009) for fructose $\left(R^{2}=0.70-0.96\right)$ and glucose $\left(R^{2}=0.70-0.85\right)$, and lower than those found for sucrose $\left(R^{2}=0.89-0.99\right)$.

However, direct comparison with other results is challenging owing to differences in the infrared regions used, detector type, and spectral measurement procedure, spectral pre-treatments method, the nature of the samples used, and partly, due to a narrow range of samples in the calibration set. The relatively poor performances of maltose and sucrose calibration models could be attributed to their relatively low concentration, and partly due to year-long storage. In addition, sugars in solution are unstable and undergo a number of 
reactions. Apart from mutarotation, which is the first reaction to occur when a sugar is dissolved, enolization and isomerization, dehydration and fragmentation, anhydride formation, and polymerization may all take place (DeMan 1999).

\section{Changes in mango fruit fructose and glucose contents as affected by fruit position in the tree canopy}

The position of a mango fruit within the tree canopy had a significant influence on the concentrations of glucose (Table 3). Fruits harvested from the outer canopy (sun-exposed) had high fructose and glucose contents compared to those harvested from within the tree canopy. Our findings are consistent with those reported for the "Mahajanaka" mango (Lueangprasert et al. 2010) and other fruits like "Kinnow" mandarin (Khalid et al. 2012) and "Fuji" apple (Jakopic et al. 2009). These results suggest that fruits in the outer portions of the canopy benefit from better light exposure and high light irradiance, which results in alterations in carbohydrate metabolism. Better light conditions are known to induce anthocyanin synthesis which results in increased levels of quercetin glycosides (Jakopic et al. 2009). Subsequently, anthocyanin syntheses in plants are depended on sunlight and sugars (Lueangprasert et al. 2010). Additionally, sunlight exposure and fruit sugars have a positive correlation with fruit skin reddening (Lueangprasert et al. 2010), an important parameter that determines consumer purchase intention. However, lack of significant differences in the concentration of fructose and glucose concentrations by some mango cultivars might be explained by low crop load in the trees at the time we were doing mango fruit harvesting. Furthermore, light exposure is a factor that differs with the position within the canopy of the fruit-bearing branch and of the fruit itself.

\section{Implications for fruit ripening stage on fructose and glucose concentrations}

Mango fruits are usually picked at the green maturity or intermediate maturity ripening stage to allow sufficient time for transport. Our results in Fig. 6 show a general trend of progressive increase in the sugar content during fruit ripening from the mature green stage to fully ripe stage. These results are consistent with reports published elsewhere (Medlicott and Thompson 1985; Vazquez-Salinas and Lakshminarayana 1985). However, high glucose content from green maturity/intermediate maturity stage to fully ripe stage is attributed to the transformation of starch into soluble sugars under the action of phosphorylase enzyme during ripening (Kansci et al. 2003). Ripening is known to induce physicochemical changes such as softening in fruits (Appiah et al. 2011). It is the sugars and organic acids which primarily contribute to the fruit taste, although in some fruits, the fruit taste can be attributed to phenolic and tanning contents (Prasanna et al. 2007). Further, low fructose concentrations at the fully ripe stage may be explained by the presence of invertase enzyme which increases in activity during ripening (Ramsey and Wang 1962). The green fruits are capable of photosynthesis, at least during the stages of ripening before the disappearance of chlorophyll (Mattoo et al. 1975). Fruits which accumulate assimilates prior to ripening can be harvested at the mature green stage and still attain acceptable flavor during ripening. This is important when considering the need for early harvest to optimize shelf life.

\section{Conclusion}

The PLS-FTIR predictive models based on reflectance mode measurements, and using the spectral range of $4000-400 \mathrm{~cm}^{-1}$, provided good estimates of mango fruit fructose and glucose concentrations, but not for sucrose and maltose sugars. By mounting the DRIFT accessory in the spectrometer's sample compartment and establishing analytical method, data acquisition time is reduced permitting large numbers of samples to be processed. All of the samples used in this study were scanned in 1 day. This provides an opportunity for using handheld FT-IR devices in the field for large-scale screening before harvesting. The sugar results confirm previous reports that fructose and glucose are the major sugars of most mango cultivars, accompanied by much smaller amounts of sucrose. Moreover, our results demonstrate the importance of better canopy management, with good light exposure on mango fruits as a way of improving quality trait such as sugars. The changes in fruit quality in response to environmental conditions may be essential in establishing optimal postharvest conditions and a decision tool when considering the need for cultivar type and location. But the lack of significant differences in fructose concentrations amongst cultivar types and sites could suggest the influence of genetic factors rather than environmental factors.

\section{Additional file}

Additional file 1: DRIFT-FTIR spectra of mango samples. (CSV $13512 \mathrm{~kb}$ )

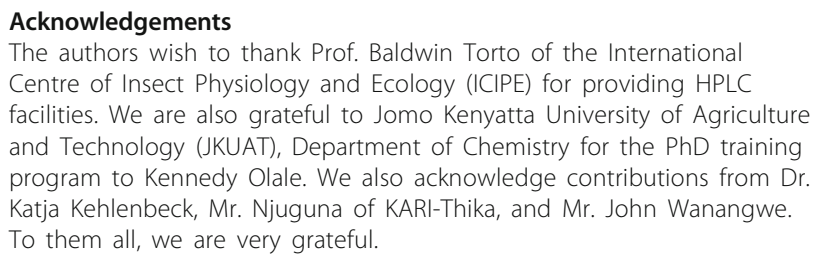

Funding

This study was supported by World Agroforestry Centre under Agriculture for Nutrition and Health (A4NH) and The National Commission for Science, Technology and Innovation (NACOSTI) PhD Grant. 


\section{Availability of data and materials}

The spectral datasets supporting the conclusions of this article are included within the article (and its Additional file 1).

\section{Authors' contributions}

$\mathrm{KO}$ performed experimental analytical work, reviewed the literature, and drafted the manuscript. WW provided guidance in drafting the manuscript and supervised the HPLC analysis. SAM provided the HPLC chemistry work and helped in designing the manuscript. AS provided guidance on R statistics spectral and experimental data analysis. KS supervised and provided guidance on IR spectral analysis and interpretation and improved the quality of the manuscript. All authors read and approved final manuscript provided guidance.

\section{Authors' information}

Kennedy Olale is a PhD student at the Department of Chemistry, Jomo Kenyatta University of Agriculture and Technology. Dr. Waudo Walyambillah holds PhD in Chemistry and is a Senior lecturer and Chair of Department of Chemistry, Jomo Kenyatta University of Agriculture and Technology. Dr. Salim Ali Mohammed. Dr. Andrew Sila holds PhD in Statistics and is also head of spectral data unit at the World Agroforestry Centre (ICRAF). Dr. Keith Shepherd serves as a Principal Soil Scientist at the World Agroforestry Centre. Keith has pioneered a Soil-Plant Spectral Diagnostics Laboratory at the Centre for high throughput analysis of soil and plant samples using only light (infrared, $x$-ray and laser spectroscopy).

\section{Ethics approval and consent to participate}

Not applicable

\section{Consent for publication}

Not applicable

\section{Competing interests}

The authors declare that they have no competing interests.

\section{Publisher's Note}

Springer Nature remains neutral with regard to jurisdictional claims in published maps and institutional affiliations.

Received: 19 September 2017 Accepted: 26 October 2017

Published online: 11 November 2017

\section{References}

Appiah F, Kumah P, Idun I. Effect of ripening stage on composition, sensory qualities and acceptability of Keitt mango (Mangifera indica). African J Food Agric Nutr Dev. 2011:11:5096-109.

Asrey R, Pal R, Sagar V, Patel V. Impact of tree age and canopy position on fruit quality of guava. Acta Hortic. 2007;735:259-62.

Beullens K, Kirsanov D, Irudayaraj J, et al. The electronic tongue and ATR-FTIR for rapid detection of sugars and acids in tomatoes. Sensors Actuators B. 2006; 116:107-15. https://doi.org/10.1016/j.snb.2005.11.084.

Brereton RG. Chemometrics: data analysis for the laboratory and chemical plant. Chichester: Wiley; 2003.

Bruno T. Sampling accessories for infrared spectrometry. Appl Spectrosc Rev. 1999:34:91-120

Bureau S, Ruiz D, Reich M, et al. Application of ATR-FTIR for a rapid and simultaneous determination of sugars and organic acids in apricot fruit. Food Chem. 2009;115:1133-40. https://doi.org/10.1016/j.foodchem.2008.12.100.

DeMan JM. Carbohydrates. Princ. Food Chem. 3rd ed. Gaithersburg: Aspen Publishers, Inc; 1999. p. 163-83.

Doreyappy-Gowda LND, Huddar AG. Studies on ripening changes in mango (Mangifera indica L.) fruits. J Food Sci Technol. 2001;38:135-7.

Duarte IF, Antonio B, Delgadillo I, et al. Application of FTIR spectroscopy for the quantification of sugars in mango juice as a function of ripening. J Agric Food Chem. 2002;50:3104-11

Griesbach J. Mango growing in Kenya. Nairobi: World Agroforestry Center; 2003.

Guo J, Zhang X. Metal-ion interactions with sugars. The crystal structure and FTIR study of an SrCl2-fructose complex3585. Carbohydr Res. 2004;339:1421-6. https://doi.org/10.1016/j.carres.2004.03.004.
Guthrie J, Walsh B, Walsh K. Non-invasive assessment of pineapple and mango fruit quality using near infra-red spectroscopy. Aust J Exp Agric. 1997;37:25363. 253

Haberhauler G, Gerzabek MH. DRIFT and transmission FT-IR spectroscopy of forest soils: an approach to determine decomposition processes of forest litter. Vib Spectrosc. 1999:19:413-7.

Jakopic J, Stampar F, Veberic R. The influence of exposure to light on the phenolic content of "Fuji" apple. Sci Hortic (Amsterdam). 2009;123:234-9. https://doi.org/10.1016/j.scienta.2009.09.004.

Kansci G, Koubala BB, Lape IM. Effect of ripening on the composition and the suitability for jam processing of different varieties of mango (Mangifera indica). J Biotechnol. 2003;2:301-6.

Kehlenbeck K, Rohde E, Njuguna JK, Jamnadass R. Mango production in Kenya; Africa. In: Valavi SG, Rajmohan K, Govil JN, et al., editors. Mango Cultiv. Differ. Ctries, vol. 2. Houston: Studium Press Llc; 2012. p. 186-207.

Kehlenbeck K, Rohde E, Njuguna JK, et al. Mango cultivar diversity and its potential for improving mango productivity in Kenya. Proc. 12th KARI Bienn. Sci. Conf. November 8-12, Nairobi-Kenya. 2010.

Kennard RWW, Stone LA. Computer aided design of experiments. Technometrics. 1969;11:137-48.

Khalid S, Malik AU, Saleem BA, et al. Tree age and canopy position affect rind quality, fruit quality and rind nutrient content of "Kinnow" mandarin (Citrus nobilis lour $\times$ Citrus deliciosa Tenora). Sci Hortic (Amsterdam). 2012:135:13744. https://doi.org/10.1016/j.scienta.2011.12.010.

Kudachikar V, Kulkarni S, Prakash M, et al. Physico-chemical changes during maturity of mango (Mangifera indica L.) variety "Neelum.". J Food Sci Technol. 2001;38:540-2.

Leopold L, Diehl H, Socaciu C. Quantification of glucose, fructose and sucrose in apple juices using ATR-MIR spectroscopy coupled with chemometry. Bull UASVM Agric. 2009;66:350-7.

Liu Y, Ying Y, Yu H, Fu X. Comparison of the HPLC method and FT-NIR analysis for quantification of glucose, fructose, and sucrose in intact apple fruits. J Agric Food Chem. 2006;54:2810-5

Lueangprasert K, Uthaibutra J, Saengnil K, Arakawa O. The effects of sugar application on the concentrations of anthocyanin and flavonol of "mahajanaka" mango (mangifera indica linn. Cv. Mahajanaka) fruit. Chiang Mai J Sci. 2010;37:355-62.

Mahayothee B, Leitenberger M, Neidhart S, et al. Non-destructive determination of fruit maturity of Thai mango cultivars by near infrared spectroscopy. Proceedings of International Symposium Sustaining Food Security and Managing Natural Resources in Southeast Asia - Challenges for the 21st Century, January 8-11, Chiang Mai, Thailand. 2002.

Manthey JA, Penelope PV. Influences of harvest date and location on the levels of $\beta$-carotene, ascorbic acid, total phenols, the in vitro antioxidant capacity, and phenolic profiles of five commercial varieties of mango (Mangifera indica L.). J Agric Food Chem. 2009;57:10825-30. https://doi.org/10.1021/jf902606h.

Marques LG, Prado MM, Freire JT. Rehydration characteristics of freeze-dried tropical fruits. LWT_Food Sci Technol. 2009;42:1232-7. https://doi.org/10. 1016/j.lwt.2009.02.012.

Mattoo AK, Murata T, Pantastico EB, et al. Chemical changes during ripening and senescence. In: Pantastico EB, editor. Postharvest physiology, handling and utilization of tropical and subtropical fruits and vegetables. Westport: The AVI Publishing; 1975. p. 103-27.

Max J-J, Chapados C. Glucose and fructose hydrates in aqueous solution by IR spectroscopy. J Phys Chem A. 2007;111:2679-89. https://doi.org/10.1021/ jp066882r.

Medlicott AP, Thompson AK. Analysis of sugars and organic acids in ripening mango fruits (Mangifera indica L. var Keitt) by high performance liquid chromatography. J Sci Food Agric. 1985;36:561-6. https://doi.org/10.1002/jsfa. 2740360707

Mercadante A, Rodriguez-Amaya D. Effects of ripening, cultivar differences, and processing on the carotenoid composition of mango. J Agric Food Chem. 1998:46:128-30.

Muoki PN, Makokha AO, Onyango CA, Ojijo NK. Potential contribution of mangoes to reduction of vitamin a deficiency in Kenya. Ecol Food Nutr. 2009:48:482-98. https://doi.org/10.1080/03670240903308604.

Njuguna JK, Wepukhulu SB, Wanjala S. Mango cultivar evaluation programme in Kenya. Acta Hort. 2009:820:133-5.

Prasanna V, Prabha TN, Tharanathan RN. Fruit ripening phenomena-an overview. Crit Rev Food Sci Nutr. 2007;47:1-19. https://doi.org/10.1080/ 10408390600976841. 
R Development Core Team. R: a language and environment for statistical computing; 2014. p. 2673

Ramsey JC, Wang C. Catabolic changes in ripening tomato fruit. Nature. 1962;193: 800-1.

Rodriguez-saona LE, Fry FS, Mclaughlin MA, Calvey EM. Rapid analysis of sugars in fruit juices by FT-NIR spectroscopy. Carbohydr Res. 2001;336:63-74.

Saranwong S, Kawano S. Improvement of PLS calibration for Brix value and dry matter of mango using information from MLR calibration. J Near Infrared Spectrosc. 2001;9:287-95.

Saranwong S, Sornsrivichai J, Kawano S. Performance of a portable near infrared instrument for Brix value determination of intact mango fruit. J Near Infrared Spectrosc. 2003;11:175-81. https://doi.org/10.1255/jnirs.364.

Saranwong S, Sornsrivichai J, Kawano S. Prediction of ripe-stage eating quality of mango fruit from its harvest quality measured nondestructively by near infrared spectroscopy. Postharvest Biol Technol. 2004;31:137-45. https://doi. org/10.1016/.jpostharvbio.2003.08.007.

Schmilovitch Z, Mizrach A, Hoffman A, et al. Determination of mango physiological indices by near-infrared spectrometry. Postharvest Biol Technol. 2000;19:245-52. https://doi.org/10.1016/S0925-5214(00)00102-2.

Stevens A, Ramirez-Lopez L. An introduction to the "Prospectr" package in R. 2015. Available online at: https://cran.r-project.org/web/packages/prospectr/ vignettes/prospectr-intro.pdf. http://cran.r-project.org/web/packages/ prospectr. Assesed 1 Jan 2015

Vazquez-Salinas C, Lakshminarayana S. Compositional changes in mango fruit during ripening at different storage temperatures. J Food Sci. 1985;50:16468. https://doi.org/10.1111/j.1365-2621.1985.tb10555.x.

Watson RR, Preedy VR. Bioactive foods in promoting health: fruits and vegetables. Amsterdam: Academic Press; 2010.

Williams P, Norris K. Near-Infrared Technology in the Agricultural and Food Industries, vol. 2. St. Paul: American Association of Cereal Chemist; 2002

Wojciechowski C, Dupu N, Ta CD, et al. Quantitative analysis of water-soluble vitamins by ATR-FTIR spectroscopy. Food Chem. 1998;63:133.

Xie L, Ye X, Liu D, Ying Y. Quantification of glucose, fructose and sucrose in bayberry juice by NIR and PLS. Food Chem. 2009;1 14:1135-40. https://doi. org/10.1016/j.foodchem.2008.10.076

\section{Submit your manuscript to a SpringerOpen ${ }^{\circ}$ journal and benefit from:}

- Convenient online submission

- Rigorous peer review

- Open access: articles freely available online

- High visibility within the field

Retaining the copyright to your article

Submit your next manuscript at $\boldsymbol{s p r i n g e r o p e n . c o m ~}$ 